Annales Geophysicae (2001) 19: 991-999 (c) European Geophysical Society 2001

\title{
Tidal wind oscillations in the tropical lower atmosphere as observed by Indian MST Radar
}

\author{
M. N. Sasi, G. Ramkumar, and V. Deepa \\ Space Physics Laboratory Vikram Sarabhai Space Centre, Trivandrum 695 022, India
}

Received: 7 November 2000 - Revised: 17 May 2001 - Accepted: 18 May 2001

\begin{abstract}
Diurnal tidal components in horizontal winds measured by MST radar in the troposphere and lower stratosphere over a tropical station Gadanki $\left(13.5^{\circ} \mathrm{N}, 79.2^{\circ} \mathrm{E}\right)$ are presented for the autumn equinox, winter, vernal equinox and summer seasons. For this purpose radar data obtained over many diurnal cycles from September 1995 to August 1996 are used. The results obtained show that although the seasonal variation of the diurnal tidal amplitudes in zonal and meridional winds is not strong, vertical phase propagation characteristics show significant seasonal variation. An attempt is made to simulate the diurnal tidal amplitudes and phases in the lower atmosphere over Gadanki using classical tidal theory by incorporating diurnal heat sources, namely, solar radiation absorption by water vapour, planetary boundary layer (PBL) heat flux, latent heat release in deep convective clouds and short wave solar radiation absorption by clouds. A comparison of the simulated amplitudes and phases with the observed ones shows that agreement between the two is quite good for the equinox seasons, especially the vertical structure of the phases of the meridional wind components.
\end{abstract}

Key words. Meteorology and atmospheric dynamics (tropical meteorology; waves and tides)

\section{Introduction}

Atmospheric solar diurnal tides are global-scale 24 hour (one solar day) oscillations, which are primarily produced by solar thermal excitation of water vapour in the troposphere, and ozone in the stratosphere and mesosphere. The diurnal tidal oscillations primarily consist of a Sun-synchronous mode (following the apparent westward motion of the Sun) having a zonal wave number of 1 . This mode is often referred to as the migrating mode, which has been studied extensively and is generated as a result of zonal symmetry of the diurnal heat sources. Chapman and Lindzen (1970) had sum-

Correspondence to: M. N. Sasi (mnsasi@md4.vsnl.net.in) marised the salient features of the classical theory of tides under various simplifying assumptions, such as motionless atmosphere, zonal symmetry of the heat sources, etc. and this classical theory is successful in explaining the major features of tidal oscillations in the upper atmosphere. However, if the water vapour and ozone distribution have zonal asymmetry, solar thermal excitation of these constituents will generate tidal modes with zonal wave numbers not equal to 1. This means that solar thermal excitation will not be able to follow the apparent westward motion of the Sun. These Sun-asynchronous tidal modes are known as nonmigrating modes. Non-migrating tides may also be generated by any other zonally asymmetric diurnally varying heat sources such as planetary boundary layer heat flux (Mckenzie, 1968; Kato et al., 1982; Tsuda and Kato, 1989), solar radiation absorption by zonally varying water vapour (Forbes and Groves, 1987), latent heat release in deep convective clouds and solar radiation absorption by zonally varying water vapour (Williams and Avery, 1996; Hagan et al., 1997). Recently, Lieberman and Leovy (1995) and Ekanayake et al. (1997), have done numerical studies of non-migrating tides by incorporating a combination of these different diurnal heat sources.

The non-migrating diurnal tidal components were detected in different atmospheric parameters by several researchers. Haurwitz (1965) reported the dominance of non-migrating diurnal surface pressure oscillations over the land. Nonmigrating diurnal tides in radiosonde winds reported by Wallace and Tadd (1974) had a short vertical wavelength of $\sim 10$ $\mathrm{km}$ and those reported by Tsuda et al. (1994) over Indonesia had an even shorter vertical wavelength $(\sim 2 \mathrm{~km})$. Similar short vertical wavelength diurnal oscillations were detected in the tropical lower stratosphere in rocket measured winds (e.g. Groves, 1980; Sasi and Krishna Murthy, 1990, 1993). VHF radar measurements of lower atmospheric winds in the tropical region also showed similar non-migrating diurnal winds with short vertical wavelength (e.g. Fukao et al., 1980; Maekawa et al., 1986; Sasi et al., 1998). However, many of the observed features of non-migrating diurnal tides 
in the tropical lower atmosphere cannot be fully accounted for by the numerical models (e.g. Lieberman and Leovy, 1995; Ekanayake et al., 1997), though these models incorporate significant tidal heat sources, such as solar heating, sensible heating in the PBL and tropospheric latent heat release. The reasons for this disagreement between observation and model calculations could be either due to the neglecting of higher order modes or the non-inclusion of other heat sources, such as solar short wave absorption by clouds, or due to both.

In this paper, we report the observed features of diurnal tidal oscillations in the tropospheric and lower stratospheric horizontal winds measured by MST radar at Gadanki (13.5 $\mathrm{N}, 79.2^{\circ} \mathrm{E}$ ) in four seasons, namely, the autumn equinox, winter, vernal equinox and summer seasons. For this purpose, radar wind measurements over 18 diurnal cycles from September 1995 to August 1996 are utilised, with the number of diurnal cycles covered being 3, 7, 3 and 5 in the four seasons, respectively. An attempt is made to model the nonmigrating tidal components for Gadanki using classical tidal theory by incorporating migrating modes due to water vapour heating by solar radiation, and non-migrating modes due to PBL heat flux, latent heat and solar short wave absorption by clouds. Section 2 describes the details of the MST radar data used and the method of analysis for extracting tidal components from the radar data. A brief account of the computation of the tidal fields using classical tidal theory is given in Sect. 3. The observed tidal characteristics during different seasons in the troposphere and lower stratosphere over Gadanki are presented and discussed in Sect. 4. In this section, the simulated diurnal tidal characteristics are compared with the observed ones. A summary and conclusions are presented in Sect. 5.

\section{Data and method of analysis}

The Indian MST radar located at Gadanki $\left(13.5^{\circ} \mathrm{N}, 79.2^{\circ} \mathrm{E}\right)$ is a high power VHF radar operating at $\sim 53 \mathrm{MHz}$ in coherent backscatter mode with an average power aperture product of $7 \times 10^{8} \mathrm{~W} \mathrm{~m}^{2}$. The transmitted peak power is 2.5 MW and it is fed to the $32 \times 32$ Yagi antenna array, generating a radiation pattern with a one way beam width of $3^{\circ}$. The radar beam can be positioned at any zenith angle and for the radar observations a beam angle of $10^{\circ}$ from zenith was used for the oblique beams in addition to the vertical direction. The diurnal observations using the MST radar were conducted during the autumn equinox (September-October 1995), winter (December 1995; January-February 1996), Vernal equinox (March 1996 and April 1997) and summer (June-July 1996) seasons, yielding Doppler spectra in the height range of 3-20 km with a vertical resolution of $150 \mathrm{~m}$ for six beams (two vertical beams and four oblique beams in the north, south, east and west directions). The measurements were made every 1 hour for 24 hours, with each measurement lasting for $\sim 10$ minutes during the $3,7,3$ and 5 diurnal cycles in the autumn equinox, winter, vernal equinox and summer seasons, respectively. The hourly wind components, namely, westerly (u), southerly (v), and vertical (w) were obtained in each range bin from the line-of-sight (LOS) velocities derived from the Doppler spectra corresponding to the six beams following the same method used by Sasi et al. (1998). Briefly, the method consists of deriving the LOS velocities from the incoherently averaged Doppler spectra for each beam and deriving the wind components from the LOS velocities using a least-square method. Thus, the time series of $\mathrm{u}, v$ and $w$ were obtained for each diurnal cycle with a time resolution of 1 hour and a height resolution of $150 \mathrm{~m}$.

Only the horizontal components of the wind, namely, the zonal (u) and meridional (v) components were used for the present study. The vertical profiles of the hourly winds ( $u$ and v) were subjected to a 5 point running mean in order to limit very large short-scale fluctuations of $u$ and $v$ with height, which may be partly random and partly due to real wind shear with short vertical scales. Then the time series for a diurnal cycle in each range bin was examined for the presence of any wild point, which may be a true outlier or produced by short period large amplitude gravity waves. This was achieved by calculating the mean and the standard deviation $(\sigma)$ in each range bin and the wind value was considered an outlier if it exceeded $\pm 1.7 \sigma$ from the mean. These outliers were replaced by interpolated values from adjacent hourly bins. In practice, occurrence of such outliers were absent below about the $14 \mathrm{~km}$ height and were 1 or 2 at higher heights. The time series data for all the available diurnal cycles in each season were averaged on an hour-by-hour basis to obtain the composite cycles of $u$ and $\mathrm{v}$. This averaging has the twin advantage of smoothing out any random variations in the radar winds produced by the short-period gravity waves and building up the coherent tidal oscillations for each season. Since the time separations between the diurnal cycles are $\sim 15$ days, any inertia gravity wave with a period near 24 hours, if present, will also be smoothed out. The hourly wind values in the composite diurnal cycle in each season were subjected to harmonic analysis to extract the diurnal amplitudes and phases in the troposphere and lower stratosphere. As discussed in Sasi et al. (1998), root mean square (rms) errors in the hourly wind values at all heights were calculated for all seasons and the corresponding rms errors in the diurnal amplitudes and phases were also computed.

\section{Simulation of tidal fields using classical tidal theory}

In order to obtain model vertical profiles of amplitudes and phases of diurnal tidal winds in the lower atmosphere over Gadanki, a simplified simulation of the diurnal tidal fields using classical tidal theory was done. The heat sources considered for the simulation were primarily solar radiation absorption by water vapour in the troposphere, planetary boundary layer heat flux, and latent heat release in deep convective clouds. Recent observational studies (Cess et al., 1995; Ramanathan et al., 1995; Pilewskie and Valero, 1995) suggest that more enhanced heating of the clouds by solar short 
wave radiation takes place in the troposphere than previously thought. This enhanced absorption by clouds amounts to a globally averaged value of $\sim 25 \mathrm{~W} \mathrm{~m}^{-2}$. In view of this fact, the cloud heating assumes significance for the generation of tidal oscillations (Sasi et al., 1998; Braswell and Lindzen, 1998). In a numerical study, Braswell and Lindzen (1998) showed that inclusion of anomalous absorption of solar radiation by clouds could remove the long-standing discrepancy of diurnal migrating surface pressure amplitudes predicted by classical tidal theory. It is possible that this excess cloud heating could generate non-migrating tidal modes, as well. For the present simulation, cloud heating is also included along with the other three sources.

The notations used to denote different tidal modes are the three-index notations $(m, s, n)$, where $m$ is the frequency of the tidal oscillation, $s$ is the zonal wave number, and $n$ is the meridional index and $|n| \geq|s| ; m=1$ for diurnal and $m=2$ for semidiurnal oscillations. The zonal wave number defines the longitudinal structure of the tidal oscillation. Positive (negative) $s$ describes the longitudinal structures with phase progressing westward (eastward) with time; $s=0$ indicates a standing oscillation. The $s=1$ diurnal mode is a westward propagating mode with a single sinusoidal longitudinal structure and it is called the migrating mode because the phase structure is constant with the phase of the Sun progressing westward around the Earth. All other zonal wave numbers $(s \neq 1)$ for the diurnal tide are called non-migrating modes. The meridional index $n$ defines the latitudinal structure of the tidal oscillation. Positive $n$ means gravitational mode and negative $n$ means rotational mode. The larger value of $n$ indicates a more complex latitudinal structure and smaller vertical scale of the mode.

The observational study by Sasi et al. (1998) suggests that diurnal tides in the lower atmosphere over Gadanki are dominated by non-migrating components. Furthermore, migrating diurnal tides are primarily generated by solar radiation absorption by water vapour (Chapman and Lindzen, 1970) and non-migrating tides are primarily generated by other diurnal sources, such as planetary boundary layer heat flux and latent heat release in clouds. A recent study by Willams and Avery (1996) of the diurnal deep convective activity (DCA) based on infrared radiance measured by four geostationary and two polar orbiting satellites shows that westward propagating nonmigrating modes with zonal wave number of 5 and eastward propagating non-migrating modes with a zonal wave number of 3 are dominantly present (in addition to the zonal wave number 0 ) in the two equinox seasons and the winter seasons. For the summer season, the zonal wave number distribution of the diurnal DCA is distinctly different from the other 3 seasons. Tsuda and Kato (1989) has shown a similar zonal wave number distribution with the dominance of +5 and 3 zonal wave numbers for the diurnal PBL heat flux. Thus, it appears that diurnal heating due to both latent heat release in deep convective clouds and planetary boundary layer heat flux are strongly linked to the land-sea distribution, as noted by Williams and Avery (1996).

The latent heat source drives migrating diurnal modes as well, which are weak when compared to the non-migrating modes (Williams and Avery, 1996). A similar argument is also valid for PBL (e.g. Tsuda and Kato, 1989). In the present work, it is assumed that for diurnal solar short wave heating of clouds, a dominance of non-migrating modes also exists. Similarly, water vapour drives non-migrating modes as well. It is known that diurnal non-migrating modes generated by water vapour heating is very weak when compared with the $(1,1,1)$ migrating mode, which is stronger by an order of magnitude (e.g. Groves, 1982). As far as ozone diurnal heating is concerned, the large vertical extent of the heating region $(20-80 \mathrm{~km})$ causes destructive interference of the short-wavelength diurnal modes and is practically ineffective in contributing to the diurnal tidal fields in the lower atmosphere. One of the early studies, using classical theory, by Lindzen (1967) shows that the contribution from ozone (including propagating $(1,1,1),(1,1,3)$ and $(1,1,5)$ modes) to the diurnal tidal winds is less than $0.3 \mathrm{~m} \mathrm{~s}^{-1}$ below 20 $\mathrm{km}$ in the low latitude region. This amplitude is definitely an order of magnitude less than the contribution from the non-migrating diurnal modes. We have incorporated $(1,1,1)$ ozone heating rates taken from Groves (1982b) in our present model and the result of the simulation shows that there is hardly any impact on the total tidal field in the altitude region below $20 \mathrm{~km}$. However, in the present simulation of diurnal tides, we have included only migrating modes due to water vapour heating, non-migrating modes due to PBL heating, latent heat and solar short wave heating of clouds. For the present simulation, only zonal wave numbers +5 and 3 were used for both latent heat release and PBL heating. Furthermore, for planetary boundary layer heat flux, one westward propagating non-migrating mode $(1,5,16)$ with a short vertical wavelength of $\sim 3 \mathrm{~km}$ was included, thus taking into account the narrow vertical extent of the diurnal heating region. For similar reasons, this mode was included for diurnal cloud heating, which is expected to have a very narrow heating region in the vertical direction. However, although we have neglected the non-migrating modes of water vapour heating, they could become important in the mesospheric-lower thermospheric region (Forbes and Groves, 1987). For all the seasons, only one simulation was done using an average diurnal heating rate for different heat sources.

As discussed above for the present simplified simulation, only migrating modes $(1,1,1),(1,1,-2),(1,1,-4),(1,1$, $-6),(1,1,-1),(1,1,-3),(1,1,3)$ and $(1,1,2)$ were used for water vapour heating rates taken from Groves (1982a). For planetary boundary layer (PBL) heating, westward and eastward travelling non-migrating modes $(1,5,5),(1,5,6)$, $(1,5,7),(1,5,8),(1,5,10),(1,5,16),(1,-3,3)(1,-3$, $4)$ and $(1,-3,5)$ were used. The vertical structure of the heating rates of all these modes corresponding to the diurnal PBL heating had an e-folding depth of $\sim 1.5 \mathrm{~km}$ with the maximum occurring at the surface. The heating rate values at the surface varied from $125 \mathrm{~mW} \mathrm{~kg}{ }^{-1}$ to $10 \mathrm{~mW} \mathrm{~kg}-1$ for the different modes. For heating rates due to latent heat release, nonmigrating modes $(1,5,5),(1,5,6),(1,5,7),(1$, $5,8),(1,5,10),(1,-3,3),(1,-3,4)$ and $(1,-3,5)$ were 


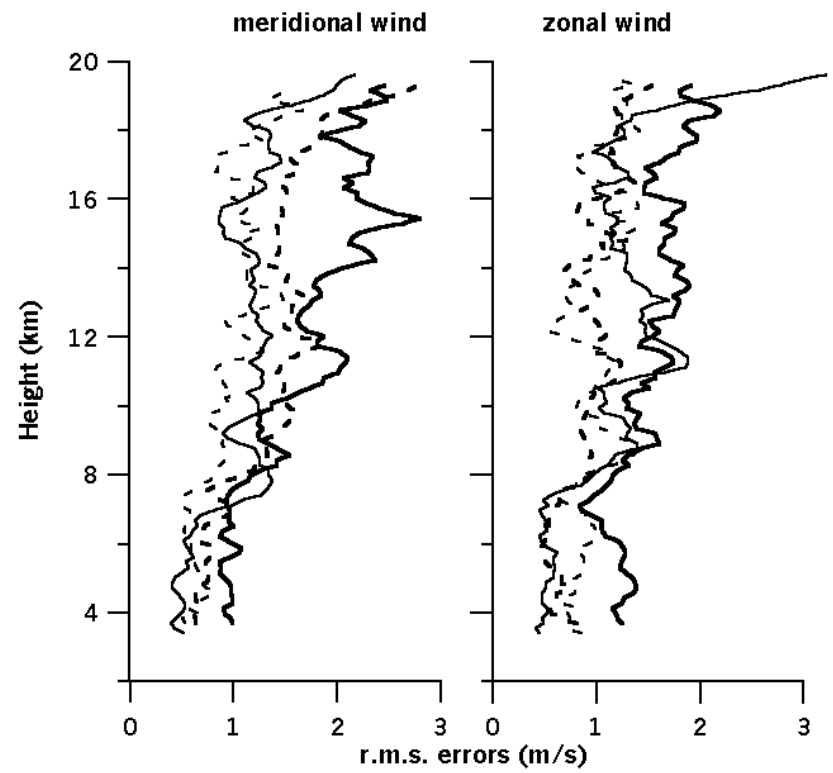

Fig. 1. Vertical profiles of rms deviations (errors) in hourly averaged meridional (left panel) and zonal winds (right panel) for the autumn equinox (thin line), winter (thick dashed line), vernal equinox (thin dashed line) and summer (thick line) seasons.

used. The vertical extent of the heating region extended from $\sim 1 \mathrm{~km}$ to $\sim 14 \mathrm{~km}$ with a broad maximum at $\sim 9 \mathrm{~km}$. The maximum heating rate values varied from $\sim 7 \mathrm{~mW} \mathrm{~kg}^{-1}$ to $0.7 \mathrm{~mW} \mathrm{~kg}^{-1}$ for different modes. For the cloud heating, only two non-migrating modes were considered, namely, (1, $-3,5)$ and $(1,5,16)$ with a narrow peak centered at $\sim 8$ $\mathrm{km}$. The e-folding depth of the heating region was $\sim 2 \mathrm{~km}$ with maximum values varying from $\sim 80 \mathrm{~mW} \mathrm{~kg}^{-1}$ to 10 $\mathrm{mW} \mathrm{kg}{ }^{-1}$.

These above Hough modes, each of which has its own characteristic vertical structure and the corresponding latitudinal structure, corresponding to different diurnal heat sources were used for computing the tidal response of the lower atmosphere up to a $20 \mathrm{~km}$ altitude using classical tidal theory. These simulated amplitudes and phases of the diurnal tidal wind components correspond to a single season, as seasonal variation of the diurnal heat sources are not taken into account.

The classical theory of tides, which is used for the simulation of diurnal tides, has many limitations. One major limitation of the theory is the assumption of a motionless atmosphere. But the zonal mean winds present in the atmosphere can affect the propagation of the diurnal tidal oscillations through it, by changing the intrinsic phase speed of the waves and Doppler shifting the intrinsic frequency of the diurnal tidal oscillations. Strong zonal winds can Doppler shift the frequency to such an extent that the latitudinally confined (within $\pm 30^{\circ}$ ) tidal modes in a motionless atmosphere can undergo vertical propagation beyond a $30^{\circ}$ latitude. However, recent studies (including the effects of background winds) show that non-migrating diurnal tides in the lower atmosphere are primarily confined to the tropical region (e.g. Ekanayake et al., 1997). Hence, it is reasonable to assume that propagation of the diurnal tides in the tropical lower atmosphere is essentially affected by the mean zonal winds in the tropics, which generally very weak in the tropical lower atmosphere and can attain magnitudes as large as 25-30 $\mathrm{m} \mathrm{s}^{-1}$ only (CIRA86, 1990). For the migrating and non-migrating modes which we have included in the present simulation of diurnal tides, the propagation of the tidal oscillations are not significantly affected by the mean winds, due to the large phase speed of these oscillations, which range from $\sim 500$ to $\sim 100 \mathrm{~m} \mathrm{~s}^{-1}$. Therefore, simulation of diurnal tidal fields including the above mentioned modes using classical theory will yield reasonable results in the tropical lower atmosphere. However, if larger zonal wave number modes are included, then the effects of mean winds on the tidal fields have to be considered. Another assumption is the independence of different Hough modes. In a real atmosphere, mode-coupling is observed, in which case the modes not present in the excitation sources are generated. But the classical theory cannot take into account this mode-coupling. However, this process may be neglected in the lower atmospheric region.

\section{Results and discussion}

The number of diurnal cycles of wind data used during the vernal equinox, winter, spring equinox and summer are 3,7 , 3 and 5 , respectively. First, the rms deviation in every hourly mean wind value (which is the mean of the hourly values in different diurnal cycles) at each height is computed under the assumption that the differences between the mean and the individual diurnal cycle values arise due to random variations (instrumental as well as natural atmospheric variability due to high frequency motions such as gravity waves). Even if the deviations occur due to the actual atmospheric motions alone, such as gravity waves, for diurnal tidal oscillations they will appear as random errors due to the lack of gravity wave coherence for an interval of nearly two weeks (which is the period between the individual diurnal cycles). So the rms values of these differences are taken as rms errors in the hourly mean wind values, which are shown in Fig. 1 for the different seasons. It is easily seen that the rms deviations (errors) are less than $2 \mathrm{~m} \mathrm{~s}^{-1}$ in all the height regions, with smaller $\left(<1 \mathrm{~m} \mathrm{~s}^{-1}\right)$ values occurring in the lower troposphere and higher values in the upper troposphere and lower stratosphere. For the summer season, the meridional wind shows larger $\left(>2 \mathrm{~m} \mathrm{~s}^{-1}\right)$ values in the height region above $14 \mathrm{~km}$. It may be noted that during the summer season a tropical easterly jet is present in this height region with its core around the $15 \mathrm{~km}$ height. The enhanced rms errors seen during this season may be due to large amplitude gravity waves generated in the jet region, which propagate upwards and downwards. The rms deviations shown in Fig. 1, considered as rms errors in the hourly mean wind values, are used to compute the rms errors in the zonal and meridional wind tidal amplitudes and 


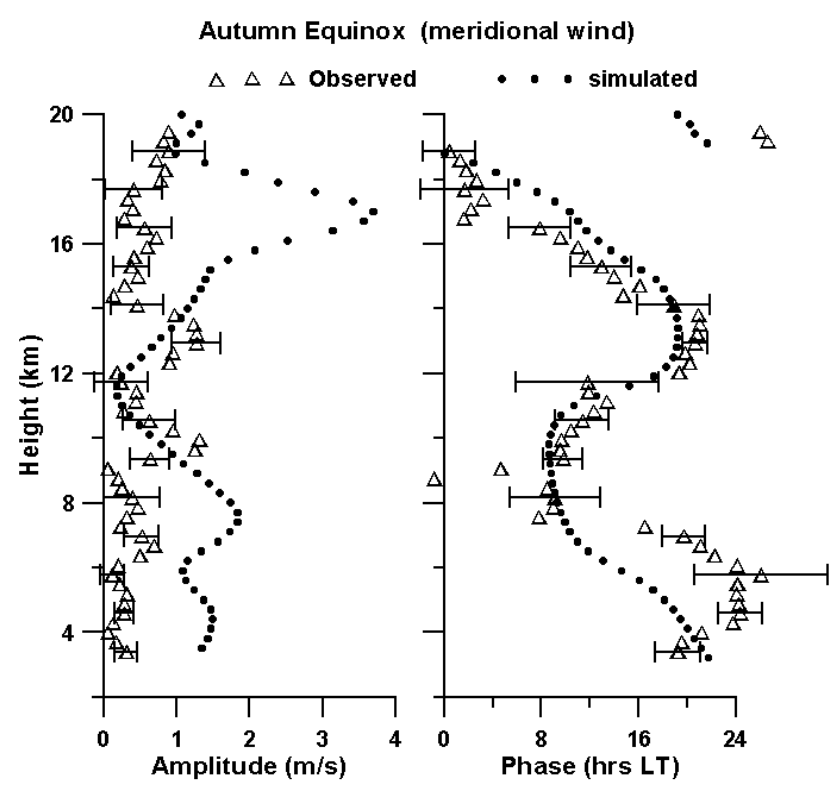

Fig. 2. Vertical profiles of amplitude (left panel) and phase (right panel) of diurnal tides in meridional winds observed over Gadanki (open triangles) during the autumn equinox season. Amplitudes and phases simulated by classical tidal theory for the location of Gadanki (same simulation for all seasons) are also shown (filled circles). The rms errors in amplitudes and phases at $\sim 1 \mathrm{~km}$ intervals are shown by horizontal bars.

phases, making use of the error propagation formulae following Whittaker and Robinson (1965).

Figures 2 and 3 show the vertical structure of the observed amplitudes and phases of the diurnal oscillation in meridional and zonal winds, respectively, during the autumn equinox season. The rms errors in the amplitudes and phases at every $\sim 1 \mathrm{~km}$ interval are shown by horizontal bars. The amplitudes are, in general, smaller below the $\sim 9 \mathrm{~km}$ height with values less than $1 \mathrm{~m} \mathrm{~s}^{-1}$ for both the meridional and zonal components. Both observed amplitudes and phases show vertical structures indicating interference of different tidal modes. Furthermore, the vertical structure of the phase shows the presence of a short vertical wavelength $(\sim 6 \mathrm{~km}$ in the lower stratosphere-upper troposphere and $\sim 3 \mathrm{~km}$ in the lower troposphere) with a negative slope, indicating upward propagation of tidal energy. There are height regions $(\sim 3 \mathrm{~km}, \sim 9 \mathrm{~km})$ where very little phase propagation exists, as can be seen in the observed vertical phase profiles of the meridional wind components (Fig. 2). The simulated amplitudes and phases of the diurnal oscillation in the meridional and zonal components of the wind are also shown in Figs. 2 and 3. It is seen that for the meridional component (Fig. 2) both the observed and simulated amplitudes and phases show vertical structures, which are very similar. Although the absolute values of the observed and simulated amplitudes differ, some of the maxima and minima in amplitude structure are reproduced. For example, amplitude minima near 6 and $12 \mathrm{~km}$ and maximum near $16 \mathrm{~km}$ are present in both the ob-

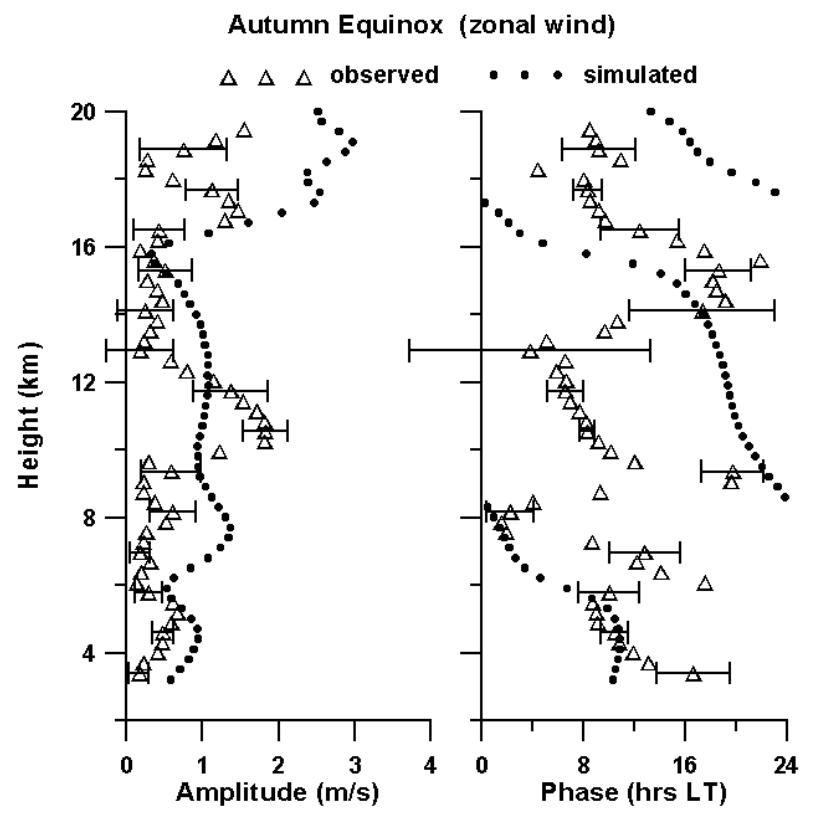

Fig. 3. Vertical profiles of amplitude (left panel) and phase (right panel) of diurnal tides in zonal winds observed over Gadanki (open triangles) during the autumn equinox season. Amplitudes and phases simulated by classical tidal theory for the location of Gadanki (same simulation for all seasons) are also shown (filled circles). The rms errors in amplitudes and phases at $\sim 1 \mathrm{~km}$ intervals are shown by horizontal bars.

served and simulated profiles. But the amplitude peak seen in the observed profile near $16 \mathrm{~km}$ height is not satisfactorily reproduced in the simulated profile, in which the peak has a much larger amplitude and is shifted in height by $\sim 1$ $\mathrm{km}$. The phase structure in the entire height region is almost reproduced in the simulated profiles. Above the $8 \mathrm{~km}$ height, observed phase values closely follow the simulated ones. For the zonal component (Fig. 3), the amplitude maxima near 5 and $8 \mathrm{~km}$ and minimum near $16 \mathrm{~km}$ are reproduced in the simulated profile as well. The observed and simulated phase profiles differ very much, unlike the phase profile of the meridional component, though in a limited altitude region (above $14 \mathrm{~km}$ ), the two profiles show downward phase propagation with similar vertical wavelengths.

In order to assess the relative contributions of different tidal excitation sources, we have done simulations using different heat sources separately. We have used the combinations of water vapour (which produces the migrating tides) and cloud, water vapour and PBL, and water vapour and latent heat for the simulations. The simulated amplitudes and phases are compared with the observed ones during the autumn equinox season. The results of the comparison show that tidal fields simulated by including water vapour and clouds reproduce many observed features of both meridional and zonal wind amplitudes. In limited height regions (15$18 \mathrm{~km}$ for meridional winds and $14-18 \mathrm{~km}$ for zonal winds), both the simulated and observed phase structures also show quite good agreement. The combination of water vapour and 


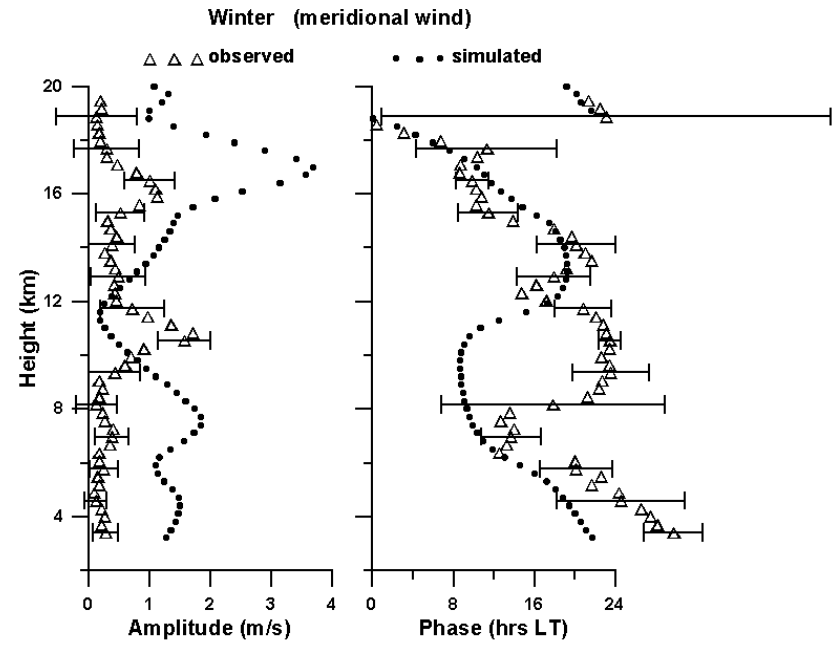

Fig. 4. Same as Fig. 2, but for the winter season.

PBL gives simulated amplitudes and phases that when compared to the observed ones, are not as good as in the case of the combination of water vapour and cloud. Nevertheless, the simulated phase of the meridional diurnal component shows quite good agreement with the observed phase in the $12-18 \mathrm{~km}$ height region. Although diurnal amplitudes of the meridional wind simulated using water vapour and latent heat show good agreement with the observed ones in limited height regions (3-7 km and 14-19 km), in general, there exist large discrepancies between the simulated and observed diurnal phases when compared to the other two cases. It was already seen that the simulated tidal fields agree better with the observed ones when all the heat sources were included in the simulation. This shows the importance of including all possible heat sources in the simulation of the diurnal tidal fields using classical tidal theory.

The diurnal amplitudes and phases of the meridional and zonal components of the winds in the winter season are given in Figs. 4 and 5, respectively. For the meridional component in winter season (Fig. 4) the observed amplitudes show 3 maxima near the 7,11 and $16 \mathrm{~km}$ altitudes and the simulated profile is able to reproduce only 2 maxima near the 7 and $16 \mathrm{~km}$ altitudes. (though with larger amplitudes). In winter, in addition, the values of the observed and simulated amplitudes differ greatly with the simulated ones being greater, except in the 10 to $13 \mathrm{~km}$ height region. The phase structures in the $12-20 \mathrm{~km}$ region in both the observed and simulated profiles lie close to each other, indicating a downward phase propagation with a vertical wavelength of $\sim 6 \mathrm{~km}$. Between 8 and $12 \mathrm{~km}$ the discrepancies between the two are large. A close examination of Fig. 4 shows that both observed and simulated phase structures show two regions of very little phase propagation, but with a mismatch in height. Apparently these observed height regions $(\sim 9 \mathrm{~km}$ and $\sim 6$ $\mathrm{km})$ have a relative shift with respect to the simulated ones $(\sim 13 \mathrm{~km}$ and $9 \mathrm{~km})$. This relative shift may be occurring due to the different height distribution of diurnal heat sources in

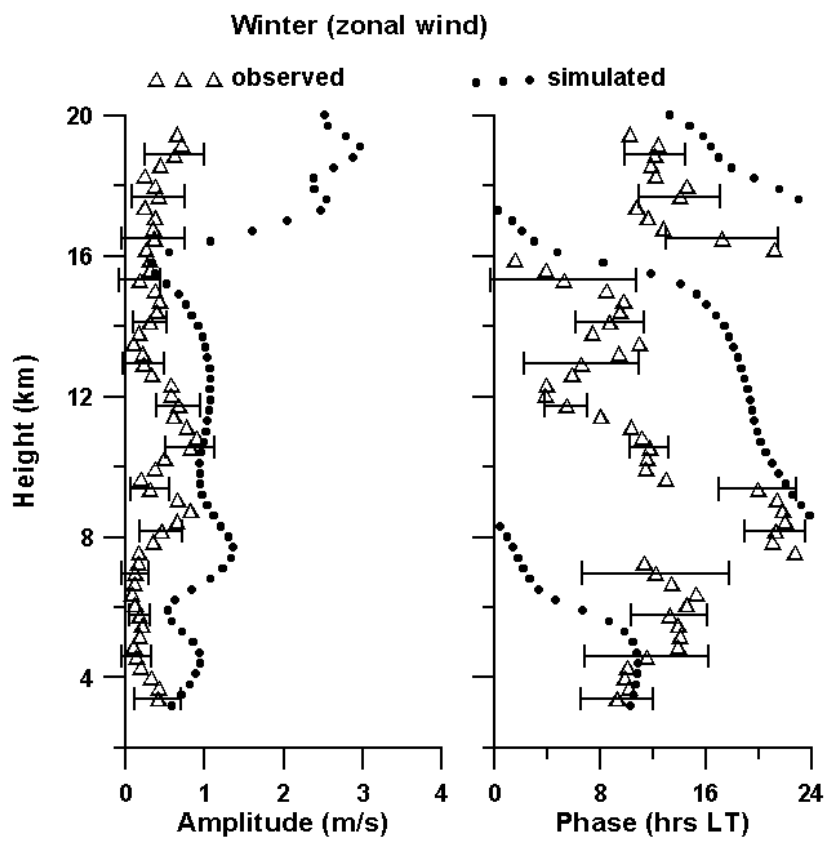

Fig. 5. Same as Fig. 3, but for the winter season.

the autumn equinox and winter. It may be noted that we have used only one set of heat sources and as such, same simulated profiles are shown for all the seasons; the difference between the observed and simulated phase profiles (Fig. 4) may be attributed to an expected seasonal variation of the distribution of the heat sources. The zonal component in the winter season (Fig. 5) shows large differences between the observed and simulated amplitude and phase structures. In the case of zonal winds, the simulated amplitudes are, in general, larger than the observed ones. The observed phase structure in the 7-12 km height region shows a clear downward propagation with a vertical wavelength of $\sim 6 \mathrm{~km}$, whereas the simulated phase profile shows a much larger vertical wavelength.

The observed vertical amplitude structures in the autumn (Fig. 2) and vernal equinox (Fig. 6) seasons show quite similar features with the amplitudes in the vernal equinox season being larger. The amplitude maxima near 5 and $10 \mathrm{~km}$ are present during both the seasons, with the amplitude significantly larger during the vernal equinox season. The observed phase structures during the two seasons (Fig. 2 and Fig. 6) are similar except for a phase difference between the two. In both the equinox seasons, the general shape of the observed vertical structures is very similar to the simulated ones. Two phase reversal regions, one near $13 \mathrm{~km}$ and the second one near $8 \mathrm{~km}$, can be clearly seen during the two equinox seasons, both in the observed and the simulated profiles. But in the case of vernal equinox season, there is a large phase difference between the observed and the simulated ones in the phase reversal region. Another interesting feature during the vernal equinox season is the downward phase propagation with a vertical wavelength of $\sim 3 \mathrm{~km}$ in the $17-20 \mathrm{~km}$ height region and $\sim 6 \mathrm{~km}$ in the $14-17 \mathrm{~km}$ height region (Fig. 6). 


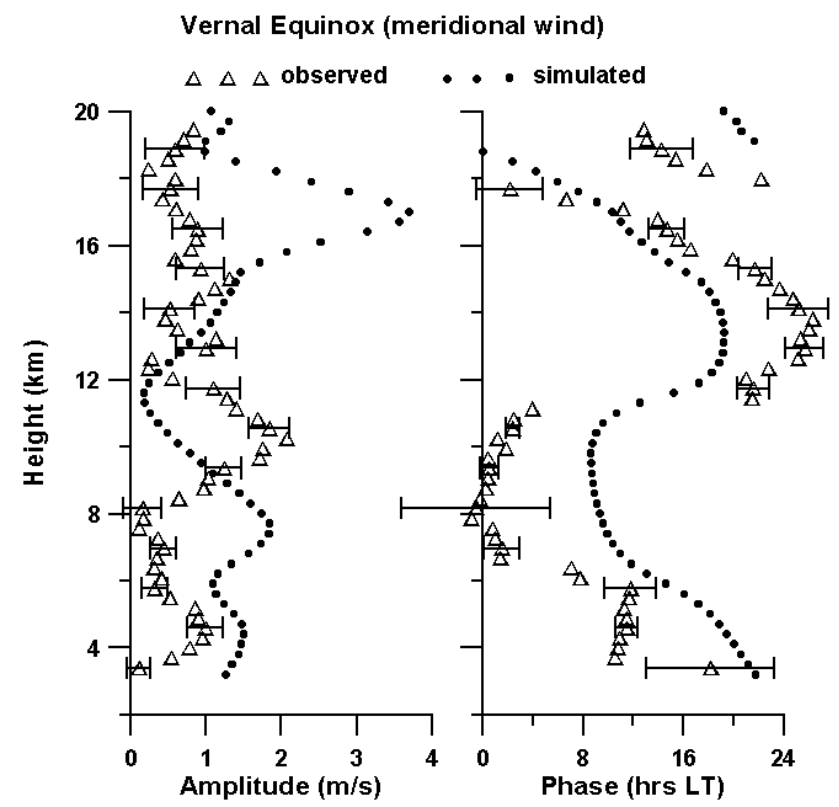

Fig. 6. Same as Fig. 2, but for the vernal equinox season.

But for the zonal components (Figs. 3 and 7), both the amplitudes and phases show large differences between the two seasons. The zonal wind amplitudes during the vernal equinox season are, in general, larger than those during the autumn equinox season, but the amplitude peaks are smaller. During the vernal equinox season the $10-17 \mathrm{~km}$ shows nearly a constant phase region and a clear downward phase propagation with a vertical wavelength of $\sim 4 \mathrm{~km}$ below the $8 \mathrm{~km}$ height region.

Although the observed diurnal amplitudes and phases of both meridional and zonal components in summer (Figs. 8 and 9) are significantly different from those during the other three seasons, the observed and simulated profiles agree with each other for a large altitude region. The observed meridional amplitudes in the 9-16 km height region and zonal amplitudes in the region below $16 \mathrm{~km}$ closely follow the simulated amplitude profiles. For the meridional diurnal wind phase (Fig. 8), there is a significant difference between the observed and simulated profiles in the 11-20 km height region. The diurnal meridional component shows a prominent amplitude maximum near the $16 \mathrm{~km}$ height during both the winter (Fig. 4) and summer (Fig. 8) seasons, whereas during the equinox (Figs. 2 and 6) seasons, this peak is somewhat suppressed. The observed diurnal phase profile for the meridional wind (Fig. 8) does not show the two phase reversal regions which are clearly seen during both the equinox seasons, one near $13 \mathrm{~km}$ and another near the $9 \mathrm{~km}$ height. Also during winter, these phase reversals can be seen, but at lower altitudes $(\sim 9$ and $\sim 6 \mathrm{~km})$. In general, the observed diurnal tidal components in winds are distinctly different from those during the other three seasons. One common characteristic observed during all four seasons is the large discrepancy between the simulated and observed phase structures

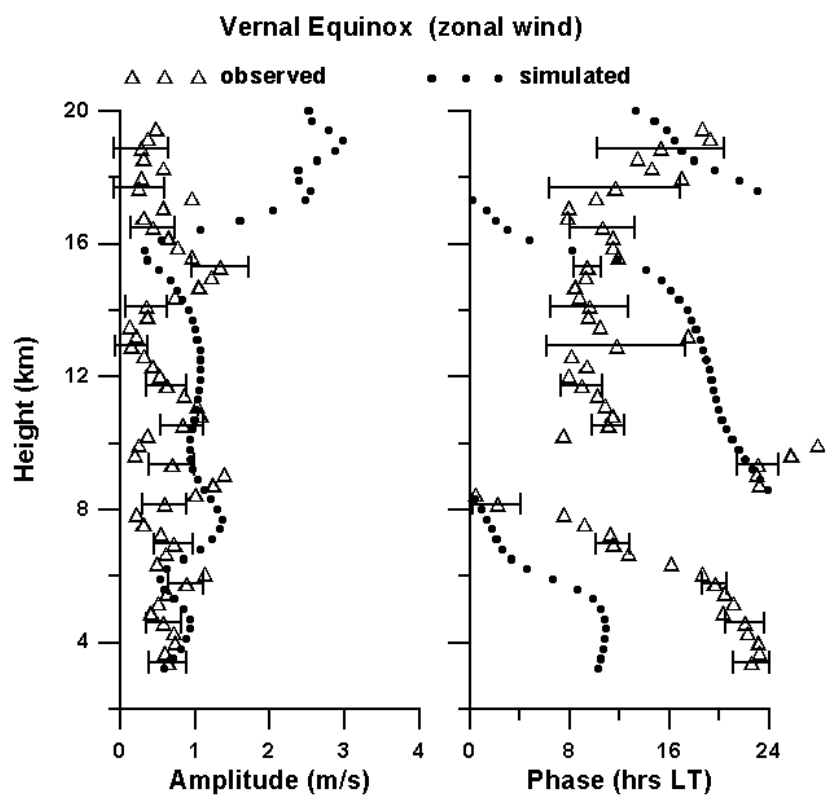

Fig. 7. Same as Fig. 3, but for the vernal equinox season.

of the diurnal zonal wind component. The exact reason for this discrepancy is not clearly identified. However, the dominance of different heat sources during the different seasons could be a plausible reason. For example, an observed zonal wind phase structure during the vernal equinox season could be reproduced reasonably well (not shown) when only water vapour and latent heat were included in the simulation. The simulated phase profile could reproduce the almost constant phase region above $\sim 10 \mathrm{~km}$ and downward phase propagation region below the $\sim 7 \mathrm{~km}$ heights.

\section{Summary}

Analysis of the MST radar winds obtained over several diurnal cycles at Gadanki in the equinox and solstice seasons during 1995-96 shows some interesting features. The vertical profile of the observed diurnal amplitude shows maxima and minima in the $3-20 \mathrm{~km}$ altitude region in all seasons. These amplitude maxima and minima at different heights, in general, show close similarities with simulated amplitude profiles, which suggests that these are produced as a result of the interference of many Hough modes generated by diurnal heat sources, such as solar heating of water vapour, planetary boundary layer heat flux, latent heat release in deep convective clouds, and solar short wave absorption by clouds in the troposphere. Similarly, there appears to be a large agreement between the vertical profile of the observed and simulated phases of the diurnal component in meridional winds during the autumn equinox and to a lesser extent during the vernal equinox season, which is again suggestive of the interference of different Hough modes in the troposphere and lower stratosphere. The difference between the simulated and observed diurnal tidal components of the meridional winds dur- 


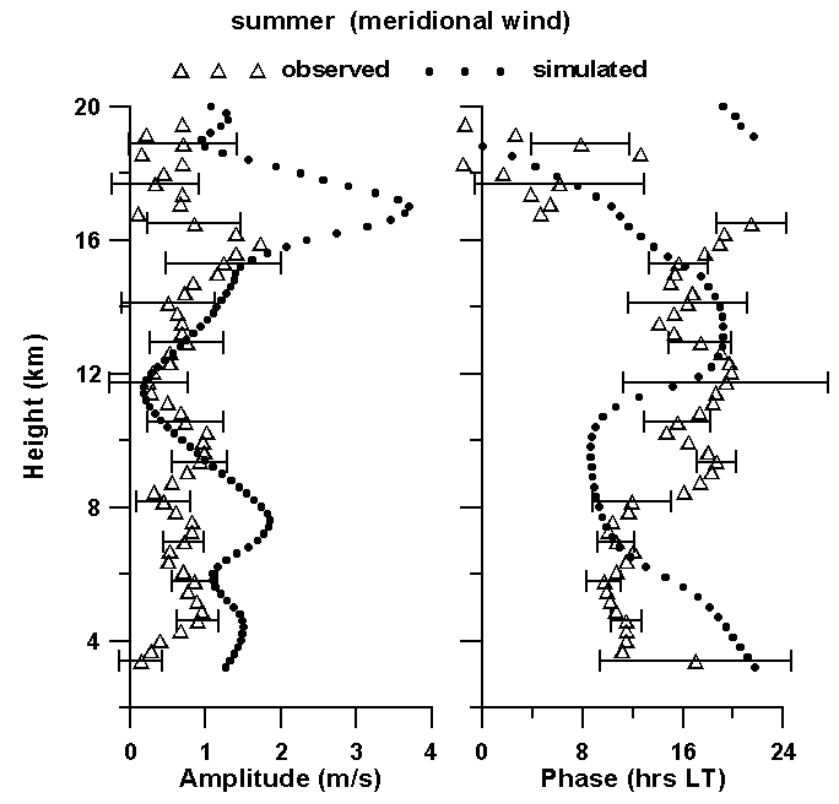

Fig. 8. Same as Fig. 2, but for the summer season.

ing the other two seasons may be attributed to the seasonal variation of the observed tidal fields, as the simulation is only for one season which roughly corresponds to the equinox season.

There exists a large disagreement between the observed and simulated phases of the zonal wind components during all the seasons. Although we could not establish a definite reason for this large discrepancy, there is an indication that this discrepancy could arise due to the dominance of different heat sources and/or the combination of different heat sources during the different seasons, as mentioned in Sect. 4. However, for this purpose a very realistic seasonal variation of different heat source characteristics (vertical distribution and dominance of different Hough modes) should be used; but the study of this particular aspect is beyond the scope of the present work. Another observation is that although the vertical profile of the diurnal phase shows upward propagation in certain height regions, it need not necessarily correspond to downward propagation of tidal energy; they are primarily the manifestations of the interference between different Hough modes. But there is also a complex situation arising from the propagation of waves from the planetary boundary layer into the mid-troposphere where other tidal sources are primarily situated.

There is apparently fairly good agreement between the observed and simulated diurnal tidal oscillation of the meridional wind during both the autumn equinox and vernal equinox (to a lesser extent) seasons, especially in the phase structure. The two height regions of phase reversal, one near $9 \mathrm{~km}$ and the second one near $13 \mathrm{~km}$, could be satisfactorily simulated, only when the cloud heating was included. This shows the importance of solar short wave heating of clouds, in addition to the other sources, such as PBL and latent heat

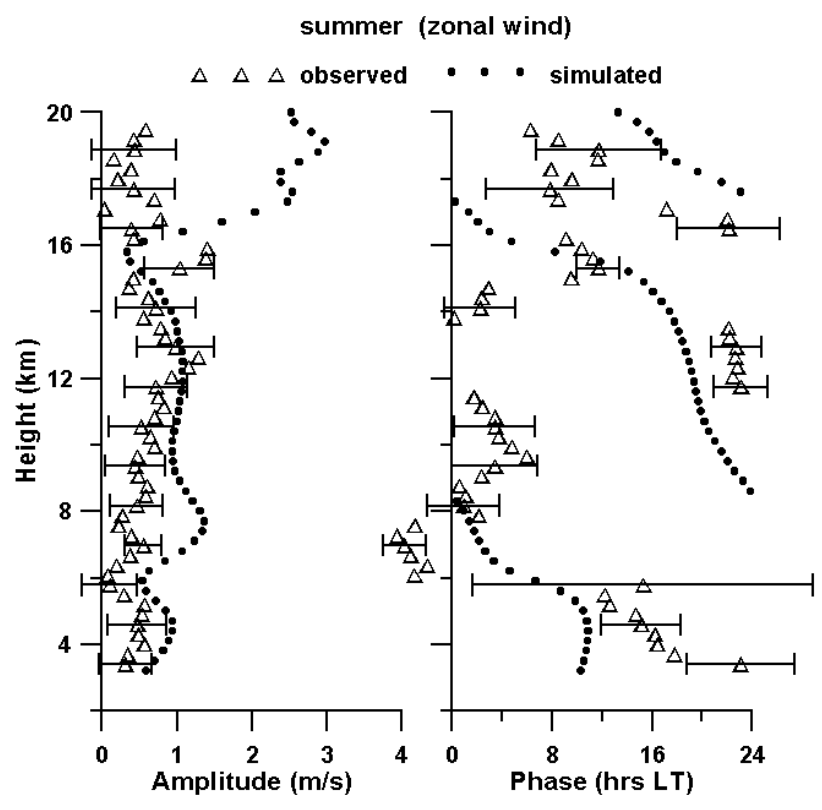

Fig. 9. Same as Fig. 3, but for the summer season.

in generating the non-migrating diurnal tidal oscillations in the lower atmosphere, similar to the findings of Braswell and Lindzen (1998) in the case of diurnal surface pressure oscillation.

Although the simulation is done using classical tidal theory and takes into account all important heat sources, the actual seasonal variation of the tidal oscillation can only be simulated by taking into account the seasonal variation of the heat sources, such as that for latent heat release reported by Williams and Avery (1996). We have not attempted here.

Acknowledgements. The authors acknowledge with gratitude the co-operation extended by the Scientific and Technical staff of National MST Radar Facility, Gadanki for running the diurnal experiments. One of the authors, V. Deepa was a recipient of ISRO Research Fellowship during the course of this work. The authors are grateful to the reviewers for their critical and constructive comments, which helped in improving the manuscript.

Topical Editor J.-P. Duvel thanks T. Aso and another Referee for their help in evaluating this paper.

\section{References}

Braswell, W. D. and Lindzen, R. S., Anomalous short-wave absorption and atmospheric tides, Geophys. Res. Lett., 25, 1293-1296, 1998.

Cess, R. D. et al., Absorption of solar radiation by clouds: Observations versus models, Science, 267, 496-499, 1995.

Chapman, S. and Lindzen, R. S., Atmospheric Tides, D. Reidel, Norwell, Mass., 1970.

CIRA86, COSPAR International Reference Atmosphere, 1986, Part II: Middle Atmosphere Models, edited by D. Rees, J. J. Barnett, and K. Labitzke, Pergamon Press, Oxford, 1990.

Ekanayake, E. M. P., Aso, T., and Miyahara, S., Background wind 
effect on propagation of nonmigrating diurnal tides in the middle atmosphere, J. Atmos. Sol. Terr. Phys., 59, 401-429, 1997.

Forbes, J. M., and Vial, F., Monthly simulation of the solar semidiurnal tide in the mesosphere and lower thermosphere, J. Atmos. Terr. Phys., 51, 649-661, 1989.

Forbes, J. M. and Groves, G. V., Diurnal propagating tides in the low-latitude middle atmosphere, J. Atmos. Terr. Phys., 49, 153164, 1987.

Fukao, S., Sato, T., Yamasaki, N., Harper, R. M., and Kato, S., Radar measurement of tidal winds at stratospheric heights over Arecibo, J. Atmos. Sci., 37, 2540-2544, 1980.

Groves, G. V., Seasonal and diurnal variations of middle atmospheric winds, Philos. Trans. R. Soc. London, Ser. A, 296, 19-40, 1980.

Groves, G. V., Hough components of water vapour heating, J. Atmos. Terr. Phys., 44, 281-290, 1982a.

Groves, G. V., Hough components of ozone heating, J. Atmos. Terr. Phys., 44, 111-121, 1982b.

Hagan, M. E., Chang, J. L., and Avery, S. K., Global-scale wave model estimates of non- migrating tidal effects, J. Geophys. Res., 102, 16439-16452, 1997.

Haurwitz, B., The diurnal surface-pressure oscillation, Arch. Meteorol. Geophys., Bioclimatol, ser. A, 14, 361-379, 1965.

Kato, S., Tsuda, T., and Watnabe, F., Thermal excitation of nonmigrating tides, J. Atmos. Terr. Phys., 44, 131-146, 1982.

Lieberman, R. S. and Leovy, C. B., A numerical model of nonmigrating diurnal tides between the surface and $65 \mathrm{~km}$, J. Atmos. Sci., 52, 389-409, 1995.

Lindzen, R. S., Thermally driven diurnal tides in the atmosphere, Quart. J. Roy. Meteorol. Soc., 93, 18-42, 1967.

Maekawa, Y., Aso, T., Rottger, J., Czechowsky, P., Rudiger, R., Schmidt, G., Hirota, I., Woodman, R. F., and Kato, S., A cooperative synchronous observation of winds and tides in the tropical lower stratosphere and mesosphere using VHF radars at Ji- camarca and Arecibo, J. Geomag. Geoelectr., 38, 81-97, 1986.

McKenzie, The diurnal atmospheric tide with Newtonian cooling and longitudinally dependent drives, $\mathrm{Ph}$. D. Thesis, University of Washington, 1968.

Pilewskie, P. and Valero, F. P. J., Direct observations of excess solar absorption by clouds, Science, 267, 1626-1629, 1995.

Ramanathan, V., Subasilar, B., Zhang, G. J., Conant, W., Cess, R. D., Kiehl, J. T., Grassl, H., and Shi, L., Warmpool heat budget and shortwave cloud forcing: A missing physics ?, Science, 267, 499-503, 1995.

Sasi, M. N. and Krishnamurthy, B. V., An observational study of middle atmospheric tides over Trivandrum ( $\left.8.5^{\circ} \mathrm{N}, 77^{\circ} \mathrm{E}\right)$, J. Geomagn. Geoelectr., 45, 547-561, 1993.

Sasi, M. N. and Krishnamurthy, B. V., Diurnal and semidiurnal tides in the middle atmosphere over Balasore $\left(21.5^{\circ} \mathrm{N}, 89.9^{\circ} \mathrm{E}\right), \mathrm{J}$. Atmos. Sci., 47, 2101-2107, 1990.

Sasi, M. N., Ramkumar, G., and Deepa, V., Non-migrating diurnal tides in the troposphere and lower stratosphere over Gadanki (13.5 N, 79.2 E), J. Geophys. Res., 103, 19485-19494, 1998.

Tsuda, T. and Kato, S., Diurnal non-migrating tides excited by a differential heating due to land-sea distribution, J. Meteorol. Soc., Japan, 67, 43-55, 1989.

Tsuda, T., Murayama, Y., Wiryosumatra, H., Harijono, S. W. B., and Kato, S., Radiosonde observations of equatorial atmosphere dynamics over Indonesia: I. Equatorial waves and diurnal tides, J. Geophys. Res., 99, 10, 491-10, 505, 1994.

Wallace, J. M. and Tadd, R. F., Some further results concerning the vertical structure of atmospheric tidal motions within the lower 30 kilometres, Mon. Wea. Rev., 102, 795-803, 1974.

Whittaker, E. and G. Robinson, The Calculus of observations, Blackie and Son Ltd., London, 1965.

Williams, C. R. and Avery, S. K., Diurnal nonmigrating tidal oscillations forced by deep convective clouds, J. Geophys. Res., 101, 4079-4091, 1996. 